\title{
NEONATAL DIPHTHERIA
}

\author{
BY \\ MICHAEL CURTIN \\ From the Child Health Clinic, City Hall, Cork
}

(RECEIVED FOR PUBLICATION NOVEMBER 27, 1952)

Several outbreaks of nasal and nasopharyngeal diphtheria in infants aged under 1 month have been recorded. O'Regan, Heenan and Murray (1943) described three separate outbreaks in a foundling hospital in Tipperary during the years 1937-41. Thirty-six infants aged under 1 month were infected and 23 died. Rolleston (1910) referred to similar outbreaks of neonatal diphtheria described in Paris and Vienna in the years 1877-87. Liakka (1947) in Finland reported 31 cases of diphtheria in the newborn with a $30 \%$ mortality, and Parish (1949) referred to local epidemics reported from Norway and Sweden. Isolated cases of neonatal diphtheria, however, are not common. Grant (1952) found only one case amongst 2,986 diphtheria admissions to Sheriff Hill Infectious Diseases Hospital, Gateshead, during the decade 1936-46, and Rolleston (1910) observed that there were only four infants aged under 2 months amongst 7,285 cases of diphtheria admitted to Grove Hospital, London.

Primary faucial diphtheria is rare during the neonatal period. McSweeney (1952) found no case of faucial diphtheria in this age group in 8,746 diphtheria cases admitted to Cork Street Fever Hospital, Dublin, in the years 1934-46 and Grant (1952) found no case of this nature in his series. The following case report of faucial diphtheria in an infant aged 22 days may therefore be of interest.

\section{Case Report}

F.C., a seventh born boy, was first seen at the Child Health Clinic, Cork, when he was 22 days old. The infant was breast fed and had progressed normally until he attained the age of 20 days. The mother then noted that he became increasingly lethargic and refused to take the breast.

On examination the infant was pale and apathetic and his cry was weak. A grey membrane covered the left tonsil, extended backwards over the posterior faucial pillar and also encroached on the anterior faucial pillar. The membrane was adherent to the underlying tissues and swabbing resulted in bleeding. There was no nasal discharge and no evidence of nasal block. The infant weighed $6 \mathrm{lb} .12 \mathrm{oz}$. and his temperature was $97 \cdot 8^{z} \mathrm{~F}$.
A clinical diagnosis of diphtheria was made and accordingly 20,000 units of antitoxin were given pending bacteriological confirmation.

On the following morning a throat swab was reported positive for $C$. diphtheriae, which on further investigation proved to be gravis in type and virulent on guinea-pig inoculation. The infant was admitted to hospital and a further 40,000 units of antitoxin were administered. On admission he was also given 500,000 units of penicillin followed by 100,000 units four-hourly. On his third day in hospital the infant suddenly collapsed due to vascular failure and was revived with difficulty. Two days later palatal paralysis with nasal regurgitation developed and this necessitated oesophageal feeding for three weeks.

Convalescence was complicated by acute otitis media but was otherwise uneventful and the infant was discharged after 164 days in hospital.

Epidemiology. All contacts were swabbed and virulent gravis-type organisms were isolated from a brother of the patient. This boy, who was aged 14 years, proved to be a symptomless faucial carrier. On questioning him it was discovered that he had prepared a feed of sugar and water two days before the baby fell ill, and before offering this bottle to the infant he sucked the teat to satisfy himself that the contents were satisfactory. He was later admitted to hospital where, despite intensive treatment with penicillin, the carrier state persisted for four months but subsequently cleared following tonsillectomy.

The level of antitoxin in the mother's blood was found to be less than 0.001 units per $\mathrm{ml}$. while the level in the case of the carrier was 10 units per $\mathrm{ml}$.

\section{Comment}

It has long been recognized that a mother transmits diphtheria antitoxin to her infant. Andrewes, Bulloch, Douglas, Dreyer, Gardner, Fildes, Ledingham and Wolf (1923) reviewed the early work of Polano (1904) and Kayser (1905) who found that the antitoxin titres of a mother and her newborn infant closely corresponded. Later von Groër and Kassowitz (1915) showed that the correspondence was not always exact, and they suggested that in some cases the placenta may hold back or selectively transmit the circulating antitoxin. This hypothesis has received additional support from the work of 
Barr, Glenny and Randall (1949) who found that in some cases the antitoxin content of cord blood was double that of mother's blood. Even allowing for selective transmission of antitoxin in some cases, it follows that in a given area the percentage of infants born with an adequate level of circulating antitoxin will depend on the immunity of the adult population. This in turn depends on such factors as the density of the population and the amount of natural and artificial immunization in the area. Thus while von Groèr and Kassowitz (1915) in Vienna found that $84 \%$ of cord bloods contained 0.005 units or more of antitoxin per ml. Randall (1949) found this level in only $70 \%$ of cord bloods in one area in London, and Barr, Glenny and Parish (1951) have recently found much lower figures in several areas in Britain.

While it has been shown that a varying percentage of infants are protected from diphtheria at birth by a blood antitoxin titre of $0.005 \mathrm{u} . / \mathrm{ml}$. or more it cannot be assumed that this protection is complete. Ipsen (1946) doubted whether any level of antitoxin gives complete assurance against infection and Hartley, Tulloch, Anderson, Davidson, Grant, Jamieson, Neubauer, Norton and Robertson (1950) showed that $36 \%$ of persons admitted to hospital with diphtheria had a blood antitoxin titre of $\mathbf{0 . 0 0 5} \mathrm{u} . / \mathrm{ml}$. or'more. It should also be noted that the antitoxin levels in these persons were indicative of a previously stimulated immunizing mechanism, and it is doubtful if similar levels obtained by placental passage would afford comparable protection. In this respect it is of interest that O'Regan and others (1950) Schick-tested six mothers whose infants developed diphtheria between the eighth and the twenty-seventh day after birth and found that all six mothers were negative to the Schick test.

In any case the protection afforded by circulating antitoxin is rapidly lost by the majority of infants during the weeks following birth. Barr and others (1949) found that the average antitoxin content of the serum of babies 10 days old was half that of cord blood and that subsequently babies lost half their antitoxin every four and a half weeks. There is, however, some evidence that antitoxin levels are better maintained in the case of breast-fed infants (von Groër and Kassowitz, 1919).

It has frequently been suggested that young infants may also be protected from diphtheria by local tissue immunity but the part which this plays is difficult to assess.

The 'isolation of infancy' is an important protective factor and may well explain the comparative rarity of sporadic cases of neonatal diphtheria. Since newborn infants are generally considered to be immune it is possible that isolated cases may be missed, especially as the disease at this age is usually nasal or nasopharyngeal in type. It has been suggested that the rarity of faucial diphtheria is due to the acid reaction of the mouth and the poor development of the tonsils in early infancy. In the case described infection by fomite transmission may have occurred and this might explain why the initial site of infection was in the fauces.

When an outbreak of neonatal diphtheria occurs in an institution all newborn infants should be given a prophylactive dose of diphtheria antitoxin. Reliance should not be placed on antitoxin administered to the mother before the infant's birth, as Chesney (1945) and Hartley (1948) have shown that heterologous antitoxin does not readily pass the placental barrier.

Before methods of protecting neonatal infants in general against diphtheria can be discussed the incidence of the disease in infants aged under 1 year must be considered. Gaffiney (1943) showed that $8 \cdot 1 \%$ of those dying from diphtheria in Dublin during the years 1936-42 were under 1 year of age and even higher figures have been found in other areas. Thus the active immunization of infants should be begun at as early an age as practicable. Young infants withstand immunization well but Vahlquist (1949) and Barr and others (1950) have shown that a passive antitoxin concentration exceeding $0 \cdot 1 \mathrm{u} . / \mathrm{ml}$. interferes with active immunization.

It has been suggested that expectant mothers should be actively immunized during the early months of pregnancy so that their infants would be born with a high titre of circulating antitoxin. While this procedure would probably afford neonatal infants a considerable degree of protection it might well interfere with early active immunization. It is tentatively suggested that it may be advisable to rely on the 'isolation of infancy' to protect neonatal infants especially since this factor probably operates most strongly during the first month of life. At the end of the first month active immunization might be begun using $0.5 \mathrm{ml}$. (25Lf) P.T.A.P. to be followed by two injections of similar dosage during the first year. Admittedly the suggested dosage is high but in a proportion of cases the initial dose will be ineffective because of residual passive immunity. The disadvantage of having to give three injections is counterbalanced by the introduction of combined antigens.

No hard and fast rules can be laid down for the immunization of young infants until an answer is obtained to many of the problems which still surround neonatal diphtheria. Not the least of these is the role played by breast feeding in the maintenance of passive immunity. 
Summen

A case of faucial diphtheria in an infant aged 22 days is described.

Reference is made to epidemics of neonatal diphtheria and to the incidence of isolated cases.

Factors which contribute to the low incidence of sporadic cases of neonatal diphtheria are mentioned.

The problem of protecting infants against diphtheria during the neonatal period and the early months of infancy is discussed.

My thanks are due to Prof. J. C. Saunders, who suggested the preparation of this paper, for much helpful advice and criticism; to Dr. H. J. Parish, of the Welloome Research Laboratories, who determined the blood antitoxin concentrations, and to Drs. T. Creedon and M. J. Lynch of the North Fever Hospital, Cork, for access to hospital records.
Repreancas

Andrewes, F. W., Bulloch, W., Douglas, S. R., Dreyer, G., Gardner, A. D. Fildes, P. Ledingham, J. C. G. and Wolf, C. G. L. (1923). Diphtheria. Med. Res. Coun. Lond, p. 288.

Barr, M., Glenny, A. T. and Parish H. J. (1951). Lancet, 1, 713.

- and Randali, K. J. (1949). Ibid., 2, 324

- - (1950). Ibid, 1, 6.

Chesney, G. (1945). Monthly Budl. Munist. Hith. Lond., 4, 144.

Gaffiney, J. C. (1943). Irish J. med. Sci., No. 208, p. 97.

Grant, J. (1952). Personal communication.

Groér, F. von and Kassowith K. (1915). Z. Immenforsch., 23, 108. - (1919). Ibid., 22, 327.

Hartley, P. (1948) Montily Budi. Minist. Hith. Land, 7, 45.

, Tulloch, W. J., Anderson, M., Davidson, W. A., Grant, J., Jamieson, W. M., Neubauer, C., Norton, R. and Robertson, G. H. (1950). Spec. Rep. Ser. med. Res. Coum. Lond, No. 272, p. 74.

Ipsen, J. (1940. J. Immunol., 54, 325.

Kayser, H. (1905) Z. klin. Med, 56, 17.

Linter, v. (1947) An. Med intern. Fenn., 36, 584.

Mesteeney, C. J. (1952). Personal communication.

O'Regan, J.'B., Heenan, M and Murray, J. (1943). Irish J. med. Sci. No. 208 , p. 116.

Parich, H. J. (1949). Proc. roy. Soc. Med, 42, 402

Polano, O. (1904). Z. Gebertsh. Gymait, 53, 456.

Randail, K. J. (1949). Proc. roy. Soc. Med., 12,404

Rolleston, J. D. (1910). Lancet, $2,947$.

Vahlquist, B. (194). Lancet, 1, 16. 